\title{
The Authorship in the Production of Open Educational Resources in the Multinational Context
}

\author{
Everton Knihs*†, Maria Amelia Eliseo*, Nizam Omar* and Ismar Frango Silveira*‡ \\ *Faculdade de Computação e Informática - Universidade Presbiteriana Mackenzie \\ ${ }^{\dagger}$ Escola de Negócios - Universidade Anhembi Morumbi \\ $\ddagger$ Universidade Cruzeiro do Sul \\ São Paulo, SP - Brazil \\ \{everton.knihs, mamelia, omar, ismar\}@mackenzie.br
}

\begin{abstract}
The concept of authorship related to the new technologies of information and communication, especially when created collaboratively, draws a discussion that presents different legal interpretations in the relations between different nations. The production of open educational resources is not a multinational context involving authors who bring with them the legal framework they are subject to. Discussing the legal elements involved with authors of a work produced in digital pallet becomes necessary for a definition of the future of the work. The resource produced in a collaborative way presents challenges not understood and adoption of a single legal proposal there are no clear legal milestones for authorship of multinational collaborative works. Copyright is suitable for this new production of collaborative works. This article presents the legal elements and how they influence the production of open educational resources, especially in the production of open text textbooks, and their production should be observed and discussed previously, in order to avoid future legal demands and evolve the legal concepts involved between different nations.
\end{abstract}

Index Terms - copyrights, author, open educational resources, licenses, authorship agreements

\section{INTRODUÇÃO}

As novas tecnologias favorecem a criação de obras intelectuais colaborativas e abertas. O processo comum de produção intelectual no ambiente virtual é considerado como um conjunto de procedimentos, onde escritores, por exemplo, escrevem, editam e publicam e o produto final desse processo é um livro texto em uma forma indivisível. Apesar deste modelo de produção intelectual, baseado em ferramentas digitais ser relativamente novo, se baseia em práticas históricas de direito autoral.

Novos enfoques e discussões legais surgem para o auxílio na criação colaborativa entre diversos autores e para concessão de licenças e intercâmbio de conteúdos, bem como novas ferramentas de colaboração, abrem oportunidades para novas formas de produção autoral. A colaboração autoral indica que um recurso aberto é resultado do processo de autoria realizada entre vários participantes. Assim, o produto final gera um debate e a necessidade de definir critérios específicos para as diversas formas de autoria para produção desenvolvida de modo colaborativo, como a dimensão legal envolvida no contexto do desenvolvimento de uma obra multinacional.

978-1-5386-3057-0/17/\$31.00 @2017 IEEE
O processo de criação e uso de Recursos Educacionais Abertos (REA), juntamente com a colaboração de conteúdos, que se deriva diretamente do caráter aberto multinacional e multicultural, oferece uma gama de novas possibilidades para a criação colaborativa de materiais e resultam em uma série de discussões que vão desde aspectos legais àquelas relativas à implementação, à adoção e às estratégias de disseminação. Dentro deste contexto, a questão da autoria e propriedade intelectual é aqui apresentada como um fator transversal e processual, ou seja, se por um lado, baseia-se no direito e licenciamento, por outro lado, a sua definição é essencial nas especificações computacionais e estratégias de adoção, que propiciam a produção e implementação da obra colaborativa criada.

Diante desse cenário, os REAs também são favorecidos e envolvem características individuais na construção do conhecimento colaborativo. A diversidade existente no aspecto multicultural, pode ser identificada quando autores de diferentes regiões, com suas particularidades em termos de saberes interagem de forma colaborativa para produção de uma obra. Os diferentes aspectos particularizados em contribuições autorais, como a formação do conhecimento, a história regional ou dos indivíduos envolvidos, o desenvolvimento social e econômico regional e individual, enriquecem o recurso educacional criado.

A criação de um recurso educacional aberto também necessita considerar a propriedade intelectual. Os limites legais surgem como forma de regulamentação e respaldo jurídico para os integrantes da produção intelectual. Assim, a dimensão cultural deve se adequar ao contexto legal, observando os limites legais multinacionais, conforme as nacionalidades dos indivíduos envolvidos em um projeto colaborativo comum. $\mathrm{O}$ recurso aberto deve respeitar as previsões legais do contexto que está inserido, observando as características multinacionais, quando surgirem conflitos ou divergências.

Neste contexto, o objetivo deste artigo é apresentar uma discussão sobre a autoria na produção de REAs criados de forma colaborativa num contexto multinacional e multicultural. Para isso, foi utilizado como estudo de caso o Projeto LATIn, cujo objetivo é a produção colaborativa de livros didáticos de textos abertos no contexto da América Latina. A 
criação destes livros, ocorrida em 2014, resultou na integração cultural e científica na América Latina. A produção intelectual proveniente auxiliou no entendimento e estudo de formas para solucionar os obstáculos legais envolvidos em uma criação multinacional, como as definições para os direitos de autor e a previsão legal para a autoria colaborativa, sendo os Acordos de Autoria com uma possível solução para os conflitos legais provenientes de relações autorais multinacionais.

Este artigo está dividido em cinco seções: esta primeira seção que apresenta brevemente a questão dos direitos autorais envolvidos na produção colaborativa de livros abertos no contexto da América Latina. A seção II que apresenta o conceito legal de autor, auxiliando no entendimento da autoria colaborativa; a seção III discute os aspectos legais envolvidos nos direitos autorais; a seção IV mostra a concessão de licenças abertas e os acordos de autoria, juntamente com o estudo de caso do projeto LATIn e finalmente, a seção V apresenta as considerações finais.

\section{O Autor e a Autoria Colaborativa}

Autor, conforme a Lei de Direitos Autorais Brasileira (LDA) n.9.610/98 [1], é a pessoa física criadora de obra literária, artística ou científica. Com isso, pode-se distinguir autor e titular, ou seja, somente a pessoa física pode ser autor, mas, esta pode transferir a titularidade de seus direitos para qualquer terceiro, pessoa física ou jurídica. Neste caso, ainda que a pessoa física seja sempre a autora da obra, o titular legitimado a exercer os direitos sobre esta pode ser uma pessoa jurídica ou física distinta do autor [11].

A autoria colaborativa possibilita um processo de interação, enriquecendo a criação produzida a partir da contribuição intelectual de cada coautor. Caracteriza-se pela coautoria e pelo trabalho em conjunto no campo intelectual. Na determinação do exercício do direito de autor, é necessário primeiro determinar quem são os autores de cada obra. Mas, no caso de criações de autoria de forma colaborativa, surge o questionamento sobre quem seriam os autores e como serão classificados.

Para se identificar como autor, poderá o criador da obra literária, artística ou científica usar de seu nome civil, completo ou abreviado até por suas iniciais, de pseudônimo ou qualquer outro sinal convencional [1] e considera-se autor da obra intelectual, não havendo prova em contrário, aquele que, por uma das modalidades de identificação referidas anteriormente, tiver, em conformidade com o uso, indicada e anunciada essa qualidade na sua utilização.

A titularidade de direitos de autor, será fornecida a quem adapta, traduz, arranja ou orquestra obra caída em domínio público, não podendo opor-se a outra adaptação, arranjo, orquestração ou tradução, salvo se for cópia da sua [1].

O reconhecimento do direito de um autor sobre seu texto [13] justifica-se devido ao vínculo intrínseco que há entre autor e sua obra. Mais do que um direito legal, a autoria é antes de tudo um direito moral, um bem não material, e também um direito econômico da exploração por quem o produziu [13]. Afirma-se, desse modo, a bipartição na conceituação da autoria, considerando-se o direito moral e o direito econômico de uma obra.

$\mathrm{O}$ direito da personalidade no ramo do direito intelectual considera o estudo dos direitos morais do autor. Contempla, dessa forma, "uma emanação da personalidade do autor e que estão intimamente ligados à relação do autor com a elaboração, a divulgação e a titulação de sua obra" [11].

Assim, os direitos morais do autor defendem o direito que o autor possui em relação a sua própria obra e que por ele deve ser exercido, desde que capaz. Caso o autor não seja capaz, ou seja, menor absolutamente incapaz ou pessoa relativa ou absolutamente incapaz, seu representante legal deverá requerêlo. Desse modo, os direitos autorais na forma econômica ou moral ficarão protegidos.

Os direitos econômicos sobre a autoria submetem a questão temporal dos direitos sobre a obra. A duração desses direitos é limitada no tempo, dependendo da legislação. O prazo mínimo de proteção estabelecida pela Convenção de Berna é de 50 anos após a morte do autor e retrata que independentemente dos direitos patrimoniais de autor, e mesmo depois da cessão dos citados direitos, o autor conserva o direito de reivindicar a paternidade da obra e de se opor a toda deformação, mutilação ou a qualquer dano à mesma obra, prejudiciais à sua honra ou à sua reputação [12].

Estes direitos são chamados de direitos morais do autor e caracterizados como forma inalienável e imprescritível. Eles fazem parte dos chamados direitos da personalidade e, por serem direitos humanos, são considerados de maneira que só o autor pode exercê-los. Em relação ao conteúdo específico dos direitos morais, não há unanimidade de critérios em distintas legislações, ou seja, o direito de paternidade da autoria e reivindicação da obra. Pode-se verificar que existe o direito de integridade do autor, que pode se opor a qualquer deformação, mutilação ou outra modificação do seu trabalho, julgando que qualquer utilização deste seria prejudicial à sua honra ou reputação.

\section{Os Aspectos Legais CONSIDERAdos dos DiREITOS AUTORAIS}

O direito autoral é um aspecto do contexto legal que envolve uma obra e deve ser levado em consideração. Os autores participantes da criação de uma obra colaborativa devem observar a questão de direito autoral que originará com sua construção. Tratando-se de autores provenientes de diferentes países na criação colaborativa de um livro didático de texto aberto, observa-se que há uma construção jurídica distinta sobre os direitos autorais nos diversos países que compõem a elaboração de uma obra, assim, o contexto legal torna-se delimitador para a produção autoral.

A formação da legislação de diferentes países possui influência do contexto cultural de um povo, desse modo, diferentes países podem originar diferentes leis ou formas diferentes de interpretar uma lei, sendo esta, interna ou externa, como convenções ou tratados internacionais. Estas diferenças podem resultar em divergências entre países ou culturas, pois cada país possui soberania sobre sua formação legal. 
Os países de origem dos autores participantes da criação de produção de um livro didático de texto aberto compartilham de um sistema de direitos autorais com base em tradição jurídica latina, que tem sua origem no direito romano-francês. Em tais legislações, ao contrário dos sistemas anglo-saxónicos, considera-se trabalhar como uma emanação da personalidade do autor, de modo a distinguir os direitos econômicos e os direitos morais [5]. Diferente da legislação latina, os sistemas de common law não consideram os direitos morais inseridos nas leis de direitos autorais, abordando principalmente os direitos patrimoniais, transformando o direito autoral como bens de consumo comercializáveis, caracterizando-os da mesma forma que bens físicos.

Nos sistemas jurídicos latinos, a proteção jurídica tornase mais complexa, devido o direito autoral envolvido e que configura-se como um direito da personalidade e direitos humanos, que somente o autor da obra poderá exercê-los.

Neste contexto, existe uma fronteira política, jurídica e cultural entre diferentes países. Como uma tentativa de abordar esta questão de forma internacional, a convenção de Berna [12] surge como principal tratado internacional sobre direitos autorais e tentativa de harmonização legal para as diferentes concepções sobre o tema. Outra forma de harmonizar as diferentes legislações foi a Organização Mundial de Propriedade Intelectual (OMPI). Trata-se de um organismo internacional responsável pelo estudo da propriedade intelectual com o intuito de proteger não somente os direitos econômicos envolvidos no direito autoral, mas também os direitos relacionados ao trabalho, criação, inovação, originalidade e os direitos morais do autor. A propriedade intelectual aplica-se para a área de conhecimento que envolve tanto patentes e desenhos industriais, direitos morais e marcas [9], desse modo, propriedade intelectual é considerada como gênero, sendo o direito autoral e a propriedade industrial consideradas espécies. Os direitos do autor são formados pelos direitos morais e patrimoniais, conforme Fig. 1.

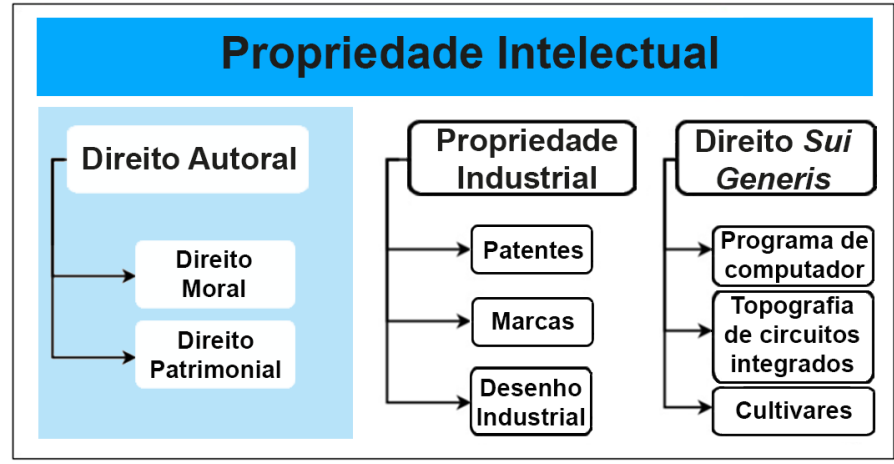

Fig. 1. Organograma da Propriedade intelectual.

Devido às possíveis fronteiras e divergências de interpretações legais entre diferentes países, a adoção de tratados e convenções internacionais por cada país torna-se necessário, bem como um consenso em sua aplicação ao caso concreto, como na elaboração e produção de uma obra colaborativa. Este consenso pode ser previsto na legislação interna de cada país ou acordado entre as partes integrantes da obra, na forma de um contrato ou acordo de autoria, baseado em normas internacionais.

A seguir, apresenta-se a divisão dos direitos autorais em direitos morais e direitos patrimoniais.

\section{A. Direitos Morais}

Os direitos morais do autor são considerados direitos da personalidade, portanto, inalienáveis e intransferíveis. Assim, mesmo que haja cessão dos direitos patrimoniais sobre a obra, o direito moral do autor é indisponível.

A criação de uma obra emana da personalidade do autor, assim surgem seus direitos morais, que são os componentes que unem o autor a sua obra, produzindo efeitos por toda sua existência, mesmo após a sua morte.

Desta maneira, os direitos morais do autor, que se referem aos bens jurídicos tutelados, são de ordem incorpórea, imaterial ou intelectual, preservando a integridade da obra.

O direito moral do autor é um direito personalíssimo e possui a finalidade de proteção do criador da obra. Esse direito possui reflexo da personalidade do autor e, assim, protegidos pelas características intrínsecas dos direitos da personalidade, como as de ser imprescritível, impenhorável, irrenunciável e inalienável.

Os direitos morais derivam da personalidade do autor, que possuem relação com a elaboração, a divulgação e a titulação de sua obra. Contrário aos direitos patrimoniais, que consistem na exploração econômica das obras protegidas [11].

\section{B. Direitos Patrimoniais}

O direito patrimonial, também chamado de direito econômico da obra, é aquele que autoriza seu titular a explorar a obra economicamente [11].

Considera-se direito patrimonial todo bem apreciável economicamente, que esteja em comércio ou que possa ser alienado ou apropriado [10]. Os direitos patrimoniais do autor nascem no momento que ele divulga a obra, através da sua comunicação ao público. Os direitos patrimoniais são considerados bens móveis, cessíveis, transferíveis e temporários. São bens transferíveis por morte e em vida.

Os direitos patrimoniais do autor reservam vantagens de ordem econômica, derivadas da exploração da obra. Estas vantagens impõem-se na autorização expressa ao legitimado, pelo autor, para qualquer uso econômico.

A criação de uma obra requer atenção em seu contexto autoral e com base na discussão vista sobre direitos autorais, surgem novas formas de autoria. A autoria colaborativa possui aspecto inovador de produção intelectual e a obra é influenciada pela interação de seus colaboradores e pelo contexto cultural que se encontram.

\section{ACordos de Autoria E Licenças Abertas: O PROJETO LATIN}

Apresenta-se, a seguir, os processos sugeridos na forma de Acordos de Autoria, possibilitando uma solução para o 
enquadramento legal multinacional de produção autoral colaborativa [7]. Estes Acordos de Autoria são considerados documentos probatórios, que devem ser registrados nos países de origem dos autores e da divulgação da obra criada e irá proporcionar aos autores colaboradores, um conjunto de critérios, tais como orientações ou sugestões. Este documento tem o intuito de programar o desenvolvimento e limitações da obra criada.

- Acordo de Autoria Coletiva: os autores possuem mesma hierarquia e a contribuição pessoal se unirá a uma criação única e autônoma, sem que seja possível atribuir a qualquer um deles, separadamente, o direito de seção de toda ou em parte da obra criada. Na autoria coletiva, é impossível atribuir a cada autor, separadamente, direito distinto em toda a obra, ou seja, uma fração ou proporção sobre a propriedade da obra completa. Os direitos econômicos pertencem à pessoa que coordenou e planejou o trabalho, salvo acordo em contrário. Os participantes serão designados "colaboradores" e o responsável pelo planejamento e coordenação será designado como "coordenador". Será necessária a adoção de uma licença para as obras derivadas desta obra original.

- Acordo de Autoria Colaborativa: os autores estão em plena igualdade e as contribuições podem ou não ser distinguíveis mas o resultado é unitário original. A criação é o resultado da colaboração conjunta dos autores. Todos os coautores são juridicamente iguais sobre os direitos econômicos, são coproprietários dos direitos autorais das criações resultantes, independentemente das contribuições que proporcionalmente representam na obra. As decisões de colaboração são feitas por unanimidade, a menos que expressamente convencionado outra solução. Neste tipo de acordo não serão definidos distintos papéis, ao atribuir a autoria, todos os participantes serão designados coautores. Será necessária a adoção de uma licença para as obras derivadas desta obra original.

- Obras Derivadas conforme o Acordo de Autoria: As Obras Derivadas recepcionam o que foi estabelecido no Acordo de Autoria e na Licença especificamente adotada na obra original. Qualquer obra derivada deve citar corretamente as obras originais. Nos processos de coautoria, com acordos coletivos ou colaborativos, devese e adaptar as definições citadas e a licença específica às obras. Nestas definições e licença, adota-se a forma de versionamento que resultará as obras derivadas.

Independente do acordo de autoria, sendo coletivo ou colaborativo, a adoção de uma licença aberta define as orientações futuras que poderão surgir com o uso e versionamento para obras derivadas, que automaticamente se enquadram e recepcionam o que está estabelecido na licença, adequando a obra derivada nas especificações e orientações da licença original determinada pelos autores.

Outro aspecto importante no processo de autoria colaborativa multinacional de recursos educacionais abertos é a adoção de licenças abertas. As licenças abertas surgem como fundamento legal, expresso pelos próprios criadores, titulares do direito autoral de uma obra, para auxiliar nas produções colaborativas. Estas produções possibilitam um movimento social em torno de uma obra, formalizando a proteção legal e autorizando previamente e expressamente suas condições de uso. Caracterizadas como uma alternativa para que o direito autoral seja preservado de acordo com os critérios de uso e derivação que o autor da obra original escolheu, baseada na adoção da licença a qual a obra será regida.

Conforme [9], como consequência do copyleft, movimento destinado à democratização dos direitos, foram introduzidas as licenças CC (Creative Commons), licenças públicas gerais, específicas para cada obra autoral, destinadas a viabilizar a livre redistribuição de obras fonográficas, científicas e literárias de acordo com a vontade do seu titular.

Existe atualmente uma série de iniciativas de REAs e, mais especificamente, de livros abertos, como Wikibooks, Booktype e Connexions, por exemplo. O projeto LATIn [8] soma-se a essas iniciativas no sentido de fornecer um conjunto de metodologias e estratégias aliadas a uma plataforma específica de software de suporte à criação, edição, reúso, remixagem e disseminação de livros-texto colaborativos abertos.

O livros didáticos de textos abertos estão protegidos pelos direitos autorais, em domínio público. Os autores disponibilizam a obra criada e abrem mão sobre o direito patrimonial que existe sobre suas criações. Seus direitos morais continuam inerentes à obra. Estes livros são publicados e disponibilizados nos meios informáticos com o intuito de universalização do conhecimento, contudo, o formato de criação é fruto de um contrato, que será definido conjuntamente, e denominado acordo de autoria [4]. Não somente o acordo de autoria, que poderá ser de forma coletiva, mas também devem ser observadas as condições de utilização da obra, chamadas de "licença".

As licenças abertas são as que garantem o direito do autor, as condições à proteção das liberdades de usar e desfrutar dos benefícios de seu uso para o trabalho, condições para utilização e, assim, facilitando futuras modificações.

Os livros didáticos de textos abertos são protegidos pelos direitos autorais, neste caso, o autor abre mão do direito patrimonial. Conforme a obra adquire características distintas, como a autoria colaborativa, que possui mais de um autor, os contratos ou acordos de autoria definem direitos e obrigações das partes envolvidas [6], e as licenças, as condições de utilização que poderá ocorrer, inclusive para obras derivadas.

$\mathrm{Na}$ escrita de livros didáticos de textos colaborativos abertos do projeto LATIn, utiliza-se uma licença aberta chamada Creative Commons Attribution-Share Alike 3.0. Esta licença possui cláusulas que interferem no exercício dos direitos patrimoniais e morais dos autores da obra [3]. Em relação aos direitos patrimoniais, o autor cede de forma exclusiva a exploração, livre distribuição e reprodução da obra e em relação aos direitos morais. $\mathrm{O}$ autor autoriza sua modificação, adaptação e redefinição [4]. Outra característica dessa forma de licenciamento, é a outorga a qualquer pessoa a possibilidade 
de reproduzir, reutilizar, adaptar, remixar, publicar ou distribuir os livros didáticos de textos colaborativos abertos, premissas do conceito de recursos educacionais abertos.

A estrutura de contratos e acordos de autoria, que definem direitos e obrigações das partes envolvidas, juntamente com a escolha da licença, que define as condições de uso de obras intelectuais [6], tornam-se necessárias para o futuro da obra. Desse modo, utilizar uma licença aberta não significa abrir mão dos direitos morais, mas de uma adaptação na era digital, com plataformas de autoria colaborativa, além de adequar a obra, observando os aspectos legais envolvidos.

A escrita de livros didáticos de textos abertos e colaborativos baseia-se em direitos de propriedade intelectual, como o direito autoral envolvido. Conforme a formação do grupo de autores, diversas culturas podem influenciar na obra, produzindo a autoria multicultural.

Foi o caso do Projeto LATIn, onde participaram nove universidades latino-americanas e três universidades européias, conforme mostra a Tabela I, sendo apenas as universidades latino-americanas, localizadas em países distintos, que colaboraram para a criação de um total de 25 livros didáticos abertos direcionados para estudantes universitários. Estes livros estão disponíveis, de forma gratuita, na biblioteca digital do projeto (http://proyectolatin.org), conforme mostra a Fig. 2 Os estudantes podem ler, imprimir e compartilhar-los [8]. Para cada livro escrito, era necessário a participação de ao menos três universidades, para que pudessem abordar características específicas da América Latina em cada um dos livros. Este caráter multicultural e multinacional permitiu o compartilhamento, de forma colaborativa, de conhecimentos e de estratégias de ensino entre os autores e coautores.

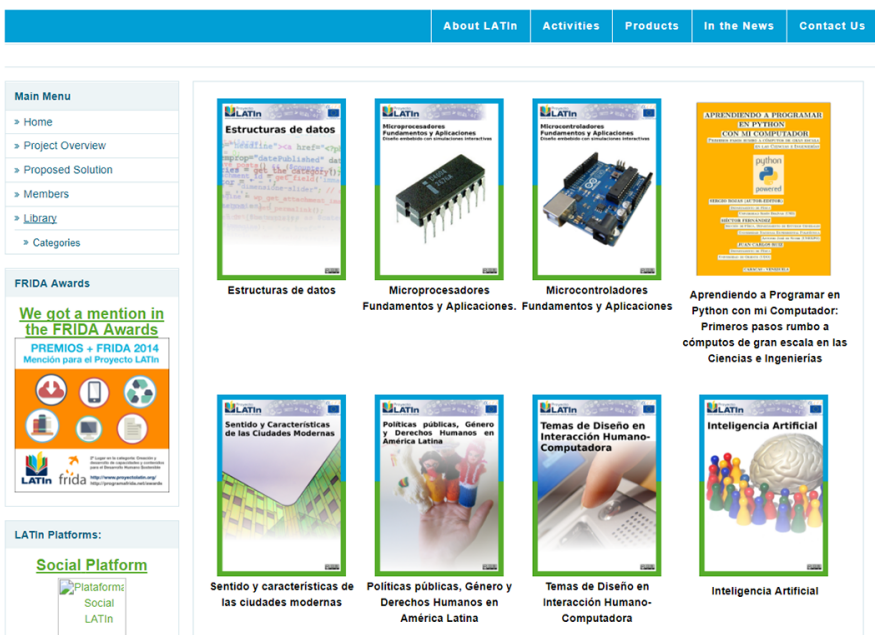

Fig. 2. Biblioteca digital do Projeto LATIn. Fonte: http://proyectolatin.org.

A escrita de cada livro, envolveu a formação de grupos de escritura que foi viabilizada por uma plataforma digital oferecido pelo Projeto LATIn, onde os professores participantes puderam interagir, discutir e trocar informações para a elaboração dos livros, vencendo, assim, os obstáculos da distância. O papel do coordenador foi fundamental para sin- cronizar, distribuir e gerenciar as atividades do seu grupo.

Com esta iniciativa, os estudantes latinoamericanos puderam ter acesso a livros didáticos abertos e adaptados ao contexto cultural da região, a um custo menor que os livros tradicionais impressos, cumprindo os objetivos do projeto.

Por terem sido produzidos por diferentes países, um dos impasses e preocupação foi a adequação das obras à previsão legal em todos os países membros do projeto, pois cada um possui soberania sobre sua legislação, mas seguem orientações conforme os tratados e convenções internacionais como signatários da OMPI quanto aos direitos autorais. Uma das soluções encontradas foram os acordos de autoria, que, com a adoção de uma licença para a produto final criado, geram amparo legal para os autores e para o recurso educacional aberto produzido.

TABLE I

UNIVERSIDADES PARTICIPANTES DO PROJETO LATIN

\begin{tabular}{c|c}
\hline Universidade & País \\
\hline \hline Escuela Superior Politécnica del Litoral (ESPOL) & Equador \\
Universidade Presbiteriana Mackenzie (UPM) & Brasil \\
Universidad de la República (UDELAR) & Uruguai \\
Universidad Nacional de Rosario (UNR) & Argentina \\
Universidad Autônoma de Aguascalientes (UAA) & México \\
Universidad Austral de Chile (UACh) & Chile \\
Universidad Central de Venezuela (UCV) & Venezuela \\
Universidad Católica San Pablo (UCSP) & Peru \\
Universidad del Cauca (UNICAUCA) & Colômbia \\
Katholieke Universiteit Leuven (KUL) & Bélgica \\
Universidad de Alcalá (UAH) & Espanha \\
Université Paul Sabatier (UPS) & França \\
\hline
\end{tabular}

No Projeto LATIn, o processo de autoria colaborativa multinacional foi considerado, conforme seus objetivos iniciais de criação, um recurso educacional aberto adquirindo os conceitos e definições de autoria e para utilização derivada, respeitando o enquadramento legal adotado.

O Acordo de Autoria adotado foi o de Acordo de Autoria Colaborativa, juntamente com a adoção da Licença Creative Commons, uma licença aberta que contribui legalmente para o Acordo sobre Obras Derivadas conforme o Acordo de Autoria, determinando como será a continuidade da obra, das contribuições futuras.

\section{CONSIDERAÇÕES FinAis}

$\mathrm{O}$ artigo apresentou como os aspectos legais interferem na produção de obras colaborativas multinacionais, como os livros didáticos de textos abertos. Uma experiência na produção de recursos educacionais abertos foi apresentada no contexto da América Latina, o projeto LATIn.

O processo de autoria leva a uma revisão dos direitos autorais em aspectos informáticos e colaborativos, uma vez que envolve a legislação de diferentes países. Deve haver uma observação e adequação às orientações de organismos internacionais [12] relacionados à propriedade intelectual, de forma a garantir direitos a todos os colaboradores, inclusive àqueles ligados às obras derivadas.

Discutiu-se o aspecto autoral de criação colaborativa de recursos educacionais abertos, descrevendo como uma obra 
pode ser criada de forma conjunta, uma produção proveniente de diversos autores. Essa colaboração significa que uma obra é fruto da autoria entre os participantes e seu produto final será uma discussão de objetivos comuns, com a construção de um conhecimento formado e estruturado colaborativamente.

Apresentaram-se os aspectos legais envolvidos no conceito de autor, a observação das licenças abertas a serem adotadas, os acordos de autorias definidos pelos autores participantes do projeto autoral e os direitos autorais envolvidos ao tema, sendo estes patrimoniais e morais.

Sugere-se a ampliação do estudo de produção e autoria colaborativa para as questões legais relacionadas ao direito da propriedade intelectual sobre o direito de áudios, imagens e vídeos em recursos abertos.

\section{REFERENCES}

[1] Brasil, Lei de Direitos Autorais n. 9.610/1998. 2. ed. So Paulo: Saraiva, 2013.

[2] M. Bordons and J. Gmez. "Collaboration networked in science", The Web of Knowledge: a festschrift in honor of Eugene Garfield, Cronin B, Atkins H, eds., New Jersey: Asis, p.197-214, 2000.

[3] Creative Commons, "Attribution-Share Alike 3.0 Unported," http://creativecommons.org/licenses/by-sa/3.0/deed.es. 2013.

[4] P. Diaz, V. Rodes, E. Knihs, N. Omar and I. F. Silveira, "Licencias y Derechos de Autoria en Textos Educativos Colaborativos Abiertos para Educación Superior," Universidad 2014 - IX Congreso Internacional de Educación Superior, V Taller Internacional "La Virtualización en la Educación Superior", 2014.

[5] J. J. G. García, "El derecho moral: Principal elemento distintivo entre el sistema latino y el anglosajón de derechos de autor", Revista de Derecho, no. 4, pp. 21-64, 2013.

[6] H. Gandelman, De Gutenberg à internet: direitos autorais na era digital, 5a. edição, Rio de Janeiro: Record, 2007.

[7] E. Knihs, "Aspectos tecnológicos, culturais e legais no compartilhamento de recursos abertos: uma caracterização da realidade Latino-Americana. Tese de Doutorado em Engenharia Elétrica e Computação, Universidade Presbiteriana Mackenzie, São Paulo, 2016.

[8] X. Ochôa; A. S. Sprock and I. F. Silveira, "Collaborative open textbooks for Latin America-The LATIn project", Proc. of ISociety 2011, pp. 398403, 2011.

[9] L. M. Paesani, Manual da propriedade intelectual, 1. ed., São Paulo: Atlas, v.1, 2012

[10] L. M. Paesani, Direito e Internet: liberdade de informação, privacidade e responsabilidade civil, 5a. ed., São Paulo: Atlas, 2012

[11] P. Paranaguá and S. Branco, Direitos autorais, Rio de Janeiro: Editora FGV, 2009.

[12] WIPO. "Convenio de Berna para la Protección de las Obras Literarias y Artísticas", http://www.wipo.int/treaties/es/ ip/berne/trtdocs_wo001.htmlP132_23079. 1979.

[13] M.Longo; S.Magnolo. The author and authorship in the internet society: new perspectives for scientific communication. Curr Sociol, n. 57(6), p. 829-850, 2009.

Everton Knihs Doutor em Engenharia Elétrica e Computação pela Universidade Presbiteriana Mackenzie. Mestre no Ensino de Matemática pela Universidade Cruzeiro do Sul. Graduado em bacharelado e licenciatura em Matemática pela Universidade Anhembi Morumbi e em Direito pela Faculdade Metropolitana Unidas, no Brasil. Atualmente é professor na Universidade Presbiteriana Mackenzie e na Universidade Anhembi Morumbi, ambas em São Paulo, Brasil, leciona Direito Digital, Lógica de Programação, Direito Aplicado a Negócios, Matemática para Gestores, Probabilidade e Estatística, Custos da Qualidade e Modelagem de Negócios e Processos.
Maria Amelia Eliseo Doutora em Engenharia de Computação pelo Instituto Tecnológico de Aeronáutica ITA (2012). Professora-Assistente da Faculdade de Computação e Informática da Universidade Presbiteriana Mackenzie. Pesquisadora do Laboratório de Computação Visual na mesma universidade, pesquisando nas áreas de Realidade Virtual e Aumentada, Tecnologias Web e Multimídia. Autora de mais de 20 artigos publicados em journals, congressos e workshops nacionais e internacionais e um capítulo de livro. Já ministrou minicursos no SVR (Simpósio de Realidade Virtual e Aumentada) e organizou eventos patrocinados pela Sociedade Brasileira de Computação - SBC (SBIE, WRVA, CBSOFT, SBGAMES).

Nizam Omar Doutor em Ciência da Computação na Pontifícia Universidade Católica do Rio de Janeiro (1989). Mestre em Matemática Aplicada (1979) e graduação em Engenharia Mecânica (1974) pelo Instituto Tecnológico de Aeronáutica - ITA, Brasil. Professor do ITA (aposentado) e atualmente professor e diretor da Universidade Presbiteriana Mackenzie. Possui experiência na área de Ciência da Computação com ênfase em Teoria da Computação, Inteligência Artificial, Linguagens Formais e Autômatos.

Ismar Frango Silveira Doutor em Engenharia Elétrica pela Universidade São Paulo (USP). Mestre em Ciência da Computação pelo Instituto Tecnológico de Aeronáutica (ITA). Bacharel em Matemática pela Universidade Federal de Juiz de Fora (UFJF), no Brasil. Professor dos cursos de pós graduação, mestrado e doutorado de Engenharia Elétrica e Computação e nos programas de Ensino de Ciências e Matemática. É coordenador da comissão de informática na educação da Sociedade Brasileira de Computação (SBC). 